\title{
MOTIVASI IBU HAMIL DALAM MENGIKUTI SENAM HAMIL DI POLINDES DESA SIMBARINGIN KECAMATAN KUTOREJO KABUPATEN MOJOKERTO
}

\author{
Wiwit Sulistyawati \\ Program Studi D3 Kebidanan STIKES Majapahit Mojokerto
}

\begin{abstract}
Pregnancy exercise is exercise that is done to prepare and train the muscles so that they can be used to function optimally in normal delivery. Pregnancy exercise is very important for pregnant women. Motivation is a stimulus or encouragement related to generating something Positive motivation can be influenced by the mother having the opportunity to have the means to do pregnancy exercise as well as support from family and closest people who provide encouragement to pregnant women. Knowledge is influenced by education, age and birth spacing as well as experience in pregnant women regarding the understanding of the benefits of pregnant exercise for pregnant women influencing pregnant women to have a strong motivation. this type of research is descriptive, the variable used is the motivation of pregnant women who do pregnancy exercise, a sample of 24 respondents, data collection techniques editing, coding, scoring, tabulating. The results showed that more than 50\% of respondents had moderate motivation to do pregnancy exercise. 13 pregnant women (54.16\%). Health workers or midwives further improve their performance in providing optimal health services by increasing quality and comprehensive services, especially in providing counseling by providing leaflets and other media to pregnant women.
\end{abstract}

keywords: motivation, pregnancy exercise

\section{A. PENDAHULUAN}

Masa kehamilan dimulai dari konsepsi sampai janin lahir. Lama kehamilan normal dihitung dari hari pertama menstruasi terakhir (HPMT) yaitu 280 hari (40 minggu atau 9 bulan 7 hari). Kehamilan dibagi menjadi 3 trimester yaitu trimester pertama mulai dari konsepsi sampai 3 bulan, trimester kedua mulai dari bulan keempat sampai 6 bulan, trimester ketiga mulai dari bulan ketujuh sampai 9 bulan (Saifuddin, 2009) selama kehamilan berlangsung banyak perubahan yang terjadi dalam tubuh seorang wanita seperti perubahan pada system reproduksi, sistem urinaria, sistem kardiovaskular, system gastrointestinal, metabolisme, sistem muskuloskeletal, system integumen, payudara, sistem endokrin, indeks massa tubuh dan beratbadan, sistem pernafasan serta sistem neurologi (Prawirohardjo, 2010)

Berdasarkan data Kementerian Kesehatan, jumlah kematian ibu mencapai 4.627 jiwa pada 2020. Angka tersebut meningkat 10,25\% dibandingkan dengan tahun sebelumnya hanya 4.197 jiwa. Penyebab kematian ibu pada tahun lalu, antara lain diakibatkan oleh pendarahan (28,29\%), hipertensi (23\%), dan gangguan sistem peredaran darah $(4,94 \%)$.

Senam hamil adalah senam yang dilakukan untuk mempersiapkan dan melatih otot-otot sehingga dapat dimanfaatkan untuk berfungsi secara optimal dalam persalinan normal. Senam hamil sangat penting bagi ibu hamil (Manuaba,2010). Senam hamil 
dimulai pada usia kehamilan antara 15 - 36 minggu. Yang boleh melakukan senam hamil ini adalah ibu hamil dengan kriteria kehamilannya sehat. Kehamilan sehat berarti ibu hamil tidak mengalami hipertensi, plasenta tidak menutupi jalan lahir, maupun hiperemisis (muntah berlebihan). Bila dipaksakan, akan berisiko mengalami perdarahan, atau bahkan keguguran (Hendrati Hapsari, 2007).

Senam hamil sangat bermanfaat untuk dilakukan selama kehamilan.Berlatih senam hamil pada masa kehamilan dapat membantu melatih pernafasan dan membuat ibu hamil merasa relaks sehingga memudahkan adaptasi ibu terhadap perubahan tubuh selama kehamilan

\section{B. TINJAUAN PUSTAKA}

\section{Konsep Dasar Motivasi}

a. Pengertian Motivasi

Motif atau motivasi berasal dari bahasa latin yaitu movere yang berarti dorongan dari dalam diri manusia untuk bertindak atau berperilaku. Motivasi inilah yang mendorong seseorang untuk berperilaku dalam pencapaian tujuan. (Notoatmodjo, 2007).

Motivasi merupakan sumber kekuatan yang mendorong seseorang menuju arah tujuan tertentu secara disadari maupun tidak disadari. (Depkes RI, 2000).

b. Proses Terjadinya Motivasi

Motivasi itu ada dan terjadi karena adanya kebutuhan seseorang yang harus segera di penuhi untuk segera beraktifitas segera mencapai tujuan. Motivasi sebagai motor penggerak maka bahan bakarnya adalah kebutuhan atau Need . Kebutuhan adalah suatu " potensi " dalam diri manusia yang perlu ditanggapi atau direspons. (Notoatmojo, 2007)

c. Pengukuran Motivasi

Motivasi tidak dapat diobservasi secara langsung namun harus diukur. pada umumnya, yang banyak diukur adalah motivasi sosial dan motivasi biologis. Ada beberapa cara untuk mengukur motivasi, yaitu :

1) Tes Proyektif : Apa yang kita katakan merupakan cerminan dari apa yang ada dalam diri kita. Dengan demikian untuk memahami apa yang dipikirkan orang, maka kita beri stimulus yang harus diinterpretasikan. Salah satu teknik proyektif yang banyak dikenal adalah Thematic Apperception Test (TAT).

2) Kuesioner: Salah satu cara untuk mengukur motivasi melalui kuesioner adalah dengan meminta klien untuk mengisi kuesioner yang berisi pertanyaan - pertanyaan yang dapat memancing motivasi klien. Sebagai contoh adalah EPPS (Edward's Personal Preference Schedule).

3) Observasi Perilaku Cara lain untuk mengukur motivasi adalah dengan membuat situasi sehingga klien dapat memunculkan perilaku yang mencerminkan motivasinya. Misalnya, untuk mengukur keinginan untuk berprestasi. Perilaku diobservasi dengan mengambil keputusan yang berisiko dan mementingkan kulitas dari pada kuantitas. (Notoatmojo, 2005) 


\section{Senam Hamil}

Senam hamil adalah latihan fisik berupa beberapa gerakan tertentu yang dilakukan khusus untuk meningkatkan kesehatan ibu hamil (Mandriwati, 2008).

Senam hamil adalah sebuah program berupa latihan fisik yang sangat penting bagi calon ibu untuk mempersiapkan persalinannya (Indiarti, 2008). Dapat disimpulkan bahwa senam hamil adalah latihan fisik ringan sesuai dengan indikasi kehamilan yang bertujuan untuk relaksasi dan persiapan saat persalinan.

Menurut Mandriwati (2008) tujuan senam hamil adalah:

a. Memperkuat dan mempertahankan elastisitas otot-otot dinding perut, ligamenligamen, otot dasar panggul yang berhubungan dengan proses persalinan.

b. Membentuk sikap tubuh, sikap tubuh yang baik selama kehamilan dan persalinan dapat mengatasi keluhan-keluhan umum pada wanita hamil, mengharapkan letak janin normal, mengurangi sesak nafas akibat bertambah besarnya perut.

c. Menguasai teknik-teknik pernafasan yang mempunyai peranan penting dalam persalinan dan selama hamil untuk mempercepat relaksasi tubuh yang diatasi dengan napas dalam, selain itu juga untuk mengatasi rasa nyeri pada saat kontraksi.

d. Menguatkan otot -otot tungkai, mengingat tungkai akan menopang berat tubuh ibu yang semakin lama makin berat seiring dengan bertambahnya usia kehamilan.

e. Mencegah varises, yaitu pelebaran pembuluh darah balik (vena) secara segmental yang tak jarang terjadi pada ibu hamil.

f. Memperpanjang nafas, karena seiring bertambah besarnya janin maka dia akan mendesak isi perut ke arah dada. Hal ini akan membuat rongga dada lebih sempit dan nafas ibu tidak bisa optimal. Dengan senam hamil maka ibu akan dapat berlatih agar nafasnya lebih panjang dan tetap relaks.

g. Latihan pernafasan khusus yang disebut penting quick breathing terutama dilakukan setiap saat perut terasa kencang.

h. Latihan mengejan, latihan ini khusus utuk menghadapi persalinan, agar mengejan secara benar sehingga bayi dapat lancar keluar dan tidak tertahan di jalan lahir

i. Mendukung ketenangan fisik

Menurut Mandriwati (2008) manfaat senam hamil adalah:

a. Mengatasi sembelit (konstipasi), kram dan nyeri punggung.

b. Memperbaiki sirkulasi darah

c. Membuat tubuh segar dan kuat dalam aktivitas sehari-hari.

d. Tidur lebih nyenyak.

e. Mengurangi risiko kelahiran prematur.

f. Mengurangi stress.

g. Membantu mengembalikan bentuk tubuh lebih cepat setelah melahirkan.

h. Tubuh lebih siap dan kuat di saat proses persalinan.

i. Bertemu dengan calon ibu lain bila ibu melakukan senam hamil 


\section{METODE PENELITIAN}

1. Jenis dan Rancang Bangun Penelitian

Jenis penelitian yang digunakan adalah Deskriptif yang menggambarkan motivasi ibu hamildalam mengikuti senam hamil

2. Populasi

Pada penelitian ini populasinya adalah semua ibu hamil yang periksa di polindes Desa Simbaringin Kec.Kutorejo kab.Mojokerto

3. Sampel dan Sampling

a) Sampel

Pada penelitian ini sampelnya adalah sebagian ibu hamil yang periksa di polindes sebanyak 24 ibu hamil

b) Sampling

Pada penelitian ini pengambilan sampel secara consecutive sampling yaitu teknik untuk menentukan sampel dari populasi secara kebetulan

4. Lokasi dan Waktu Penelitian

Penelitian ini dilakukan polindes di mulai pengambilan data bulan mei-juli 2021

5. Tehnik dan Instrumen Pengumpulan Data

a) Tehnik pengumpulan Data

Setelah mendapatkan ijin dari kepala polindes peneliti mengadakan pendekatan dengan responden untuk mendapatkan persetujuan dari responden sebagai subjek penelitian, yaitu ibu hamil Cara pengambilan data dengan membagikan kuesioner pada responden.

b) Instrumen

Instrumen yang digunakan untuk motivasi adalah kuesioner dengan menggunakan skala likert.

6. Tehnik Pengolahan dan Analisis Data.

a) Pengolahan Data

Setelah data terkumpul, maka dilakukan pengolahan data melalui tahapan Editing, Coding, Skoring, dan Tabulating. 


\section{HASIL PENELITIAN}

Tabel 1. Distribusi responden berdasarkan umur, pendidikan, paritas, di polindes desa Simbaringin kec.kutorejokab. Mojokerto, Mei - Juli 2021.

\begin{tabular}{|c|c|c|}
\hline \multirow[t]{2}{*}{ Variabel } & \multicolumn{2}{|c|}{ Total } \\
\hline & Responden & Prosentase \\
\hline \multicolumn{3}{|l|}{ Umur } \\
\hline$<20$ atau $>35$ tahun & 4 & 16.6 \\
\hline $20-35$ tahun & 20 & 83.3 \\
\hline \multicolumn{3}{|l|}{ Pendidikan } \\
\hline SD - SLTP & 2 & 8.33 \\
\hline SLTA & 18 & 75.0 \\
\hline Diploma/sarjana & 4 & 16.6 \\
\hline \multicolumn{3}{|l|}{ Pekerjaan } \\
\hline Bekerja & 10 & 41.6 \\
\hline Tidak bekerja & 14 & 58.3 \\
\hline \multicolumn{3}{|l|}{ Jarak anak } \\
\hline$<10$ tahun & 16 & 66.6 \\
\hline$\geq 10$ tahun & 8 & 33.3 \\
\hline \multicolumn{3}{|l|}{ Paritas } \\
\hline Primipara & 7 & 29.1 \\
\hline Multipara & 17 & 70.83 \\
\hline
\end{tabular}

Berdasarkan tabel 1 terlihat bahwa sampel didominasi oleh kelompok umur 20 - 35 tahun yaitu 20 responden $(83,3 \%)$, dengan berpendidikan SLTA yaitu 18 responden $(75,0 \%)$, status pekerjaan tidak bekerja sebesar 14 responden $(58.3 \%)$, jarak anak $<10$ tahun 16 responden $(66.6 \%)$, dan paritas terbanyak yaitu multipara dengan 17 responden $(70.83 \%)$. 
Tabel 2 Distribusi frekuensi Motivasi ibu hamil dalam mengikuti senam hamil di polindes Desa Simbaringi Kec.Kutorejo kab.Mojokerto bulan mei-Juli 2021

\begin{tabular}{|c|c|c|}
\hline Motivasi & Responden & Prosentase \\
\hline Kuat & 8 & 33,3 \\
\hline Sedang & 13 & 54,16 \\
\hline Lemah & 3 & 12,2 \\
\hline Total & 24 & 100 \\
\hline
\end{tabular}

Berdasarkan tabel 2 responden penelitianlebih dari 50\% ibu hamil memiliki motivasi yang sedang untuk mengikuti senam hamil di polindes Desa Simbaringin Kec.Kutorejo .yitu sebesar 13 responden ( 54,16\%)

\section{E. PEMBAHASAN}

\section{Karakteristik sosiodemografi responden}

a) Usia

Berdasarkan hasil penelitian didapatkan hamil trimester III sebagian besar berusia 20 - 35 tahun. Hal ini menunjukkan sebagian besar responden berada pada umur yang tidak berisiko. Umur merupakan rentang waktu antara saat lahir sampai saat meninggal dunia, semakin bertambahnya usia maka semakin banyak pengalaman yang didapat oleh seseorang. Hal ini dapat dimengerti karena semakin tua umur ibu maka dia akan belajar untuk semakin bertanggung jawab terhadap anak dan keluarganya. Usia ibu sangat berpengaruh pada kualitas bayi yang akan dilahirkan. Ibu yang terlalu muda tidak/ belum siap memberikan lingkungan yang diperlukan untuk pertumbuhan janin. Wanita yang melahirkan pada usia kurang dari 20 tahun atau lebih dari 35 tahun berisiko dalam melahirkan.

\section{b) Pendidikan}

Berdasarkan hasil penelitian pendidikan hamil trimester III paling banyak berpendikan SLTA. Pendidikan SLTA dikategorikan pendidikan menengah. Pendidikan secara umum adalah segala upaya yang direncanakan untuk mempengaruhi seseorang, baik secara individu, kelompok ataupun masyarakat sehingga mereka melakukan apa yang diharapkan oleh perilaku pendidikan .

Menurut Azwar bahwa tingkat pendidikan formal merupakan dasar pengetahuan intelektual yang dimiliki oleh seseoarang, hal ini erat hubungannya dengan pengetahuan semakin tinggi, tingkat pengetahuan semakin besar untuk menyerap dan menerima informasi sehingga pengetahuan dan wawasan lebih luas. Selain itu tingkat pendidikan merupakan salah satu pengetahuan yang mempengaruhi perilaku seseorang 


\section{c) Pekerjaan}

Berdasarkan hasil penelitian sebagian besar adalah bekerja. Pekerjaan adalah kegiatan rutin sehari- hari yang dilakukan oleh seorang ibu dangan tujuan untuk memperoleh penghasilan (Notoatmodjo, 2003). Bila ibu bekerja atau mencari nafkah maka akan berkurang kesempatannya atau waktunya untuk datang ke tempat pelayanan atau memperoleh informasi . ibu tersebut mendapat informasi dari teman, dan media social untuk mendapatkan informasi yang akurat, tentang keadaannya

\section{d) Paritas}

Berdasarkan hasil penelitian sebagian besar responden paritasnya adalah multipara. Paritas multipara adalah paritas dimana seorang wanita pernah melahirkan anak yang ke 2 dan seterusnya. Paritas menunjukkan jumlah kehamilan yang pernah dialami ibu serta status terminasi kehamilan tersebut. Paritas menggambarkan pengalaman ibu dalam kehamilan. Paritas multipara adalah paritas yang aman untuk hamil

\section{e) Jarak Anak}

Berdasarkan hasil penelitian sebagian besar responden jarak anaknya adalah $<10$ tahun. Jarak anak $<10$ tahun. Jarak kehamilan adalah suatu pertimbangan untuk menentukan kehamilan yang pertama dengan kehamilan berikutnya. Jarak ideal kehamilan sekurang -kurangnya 2 tahun (Judha, 2012). Proporsi kematian terbanyak terjadi pada ibu dengan paritas 1 - 3 anak dan jika dilihat menurut jarak kehamilan ternyata jarak kurang dari 2 tahun menunjukkan proporsi kematian maternal lebih banyak. Jarak kehamilan yang terlalu dekat menyebabkan ibu mempunyai waktu singkat untuk memulihkan kondisi rahimnya agar bisa kembali kondisi sebelumnya. Pada ibu hamil dengan jarak yang terlalu dekat berisiko terjadi anemia dalam kehamilan

\section{Motivasi ibu hamil dalam mengikuti senam hamil}

Berdasarkan penelitian didapatkan bahwa motivasi senam hamil pada ibu hamil di Polindes Desa Simbaringin Kec.Kutorejo didapatkan hasil 8 ibu hamil $(33,3 \%)$ memiliki motivasi yang kuat ,13 ibu hamil $(54,16 \%)$ memiliki motivasi yang sedang dan 3 ibu hamil (12,2\%) memiliki motivasi yang lemah.

Motivasi adalah ransangan atau dorongan yang berhubungan dengan membangkitkan sesuatu ( Clegg.2013). Motivasi yang positif dapat dipengaruhi oleh ibu memiliki kesempatan adanya sarana untuk melakukan senam hamil serta dukungan dari keluarga dan orang terdekat yang memberi dorongan kepada ibu hamil. Pengetahuan dipengaruhi oleh pendidikan, usia dan jarak kelahiran serta pengalaman pada ibu hamil akan pemahaman tentang manfaat senam hamil pada ibu hamil mempengaruhi ibu hamil memiliki Motivasi yang kuat.

Berdasarkan penelitian Qomqriah,2019 bahwa Motivasi ibu hamil dengan pelaksanaan senam hamil memiliki hubungan yang sangat erat. Dimana seseorang yang telah termotivasi untuk melakukan sesuatu, maka akan berusahamelakukan sesuatu tersebut dengan baik dan tekun, dengan harapan hasil yang baik.Motivasi seseorang yang disebabkan oleh kemauan sendiri bukan dari dorongan luar akan lebih menguntungkan dan memberikan keteraturan dalam 
melakukan aktivitas

\section{F. PENUTUP}

Berdasarkan pengolahan data didapatkan hasil motivasi ibu hamil dalam mengikuti senam hamil lebih dari $50 \%$ responden memiliki motivasi yang sedang, yaitu 13 ibu hamil $(54,16 \%)$.

\section{G. DAFTAR PUSTAKA}

Alex Sobur. 2003. Psikologi Umum. Bandung : Pustaka Seti

Asnawi, Sahlan. 2007. Teori Motivasi Dalam Pendekatan Psikologi Industri dan Organisasi. Jakarta: Studia Press.

Hendrati \& Hapsari. (2008). Senam Hamil Bantu Kelahiran Si Buah Hati. Jakarta ; EGC

Indriati, E. 2010., Antropometri Untuk Kedokteran, Keperawatan, Gizi, dan Olahraga. Yogyakarta: Citra Aji Parama

Maryunani \& Sukaryati. (2011). Senam Hamil, Senam Nifas, dan Terapi Musik. Jakarta : Trans Info Media

Mandriwati, G.A. 2008. Penuntun Belajar Asuhan Kebidanan Ibu Hamil. Jakarta: ECG

Mubarok. (2007). Promosi Kesehatan Sebuah Pengantar Proses Belajar Mengajar Dalam Pendidikan. Yogyakarta. Graha Ilmu.

Notoadmodjo,2005, Metodologi Penelitian Kesehatan, Jakarta: Rineka Cipta

Notoatmodjo, 2007. Promosi kesehatan dan ilmu perilaku.Jakarta: Rineka Cipta

Salmah, dkk. (2006). Asuhan Kebidanan Antenatal. Jakarta : EGC

Siti Qomariah, 2019 "Hubungan Motivasi Terhadap Pelaksanaan Senam hamil Pada Ibu hamil Trimester III di BPM HJ.Dince Safrina ,SST Pekan Baru” Journal Of Midwifery Science vol 3,no 1,46-39.

Supriatmaja, dkk. (2005). Pengaruh senam hamil terhadap kala satu dan kala dua. Denpasar : FKMUI 